\title{
ARTIGOS
}

Submetido em 13.01.2014. Aprovado em 22.01.2015

Este artigo tem coautoria de membro do Corpo Editorial da RAE, foi avaliado em double blind review, com isenção e independência. Editor Científico: Felipe Zambaldi

DOI: http://dx.doi.org/10.1590/So034-759020150602

\section{FOCO REGULATÓRIO E CONSUMO DE BEBIDA: REDUZINDO A INTENÇÃO DE BEBER E DIRIGIR}

\author{
Regulatory focus and drinking behavior: decreasing the intention to drink and drive \\ Foco regulatorio y consumo de bebida: reduciendo la intención de beber y conducir
}

\begin{abstract}
RESUMO
Zhao e Pechmann (2007) usaram a teoria de foco regulatório e a estrutura da mensagem e mostraram que houve, na média, $14,4 \%$ de aumento da intenção de não fumar entre sujeitos expostos a mensagens de comunicação congruentes com o perfil do indivíduo. Neste artigo, ampliamos o campo do estudo aplicando o foco regulatório nas comunicações contra consumo de álcool. Sugerimos que a intenção de beber e dirigir e de convencer os amigos a não beber e dirigir é condicionada à emoção (culpa vs. vergonha), à estrutura da mensagem (positivo vs. negativo) e à interdependência do indivíduo (eu vs. outro sofrendo danos). No primeiro experimento, não apenas o foco regulatório modera a relação entre beber e convencer os amigos a não beber e dirigir, como também o frame da mensagem interagiu. No segundo experimento, a emoção e interdependência do indivíduo interagem com o hábito de beber álcool e afetam ambas as variáveis dependentes.
\end{abstract}

PALAVRAS-CHAVE | Promoção, prevenção, bebida, emoção, mensagem.

\begin{abstract}
Zhao and Pechmann (2007) used regulatory focus theory and message framing, to find an average $14.4 \%$ increase in the intention not to smoke when the campaign was consistent with the profile of individuals. In this article, we expand that study to apply regulatory focus theory to campaigns against alcohol consumption. We suggest that the intention to drink and drive and the intention to convince friends not to drink and drive are determined by emotion (guilt vs. shame), message framing (positive vs. negative framing), and individual interdependence (me vs. others affected). In the first experiment, we found that not only does regulatory focus moderate the relationship between drinking and persuading friends not to drink and drive, but message framing also has an impact. In the second experiment, we found that emotion and individual interdependence has an effect on the habit of drinking alcohol and affects both dependent variables.
\end{abstract}

KEYWORDS I Promotion, prevention, drinking, emotion, message.

\section{VALTER AFONSO VIEIRA}

valterafonsovieira@gmail.com Professor da Universidade Estadual de Maringá, Programa de PósGraduação em Administração Maringá - PR, Brasil

\section{EDUARDO ANDRÉ TEIXEIRA AYROSA} eayrosa@gmail.com

Professor da Universidade do Grande Rio, Programa de Pós-Graduação em Administração - Rio de Janeiro - RJ, Brasil

\section{RESUMEN}

Zhao y Pechmann (2007) usaron la teoría de foco regulatorio y la estructura del mensaje y mostraron que hubo, en promedio, $14,4 \%$ de aumento de la intención de no fumar entre sujetos expuestos a mensajes de comunicación congruentes con el perfil del individuo. En este artículo, ampliamos el campo de estudio aplicando el foco regulatorio en las comunicaciones contra el consumo de alcohol. Sugerimos que la intención de beber y conducir y de convencer a los amigos a no beber y conducir está condicionada a la emoción (culpa vs. vergüenza), a la estructura del mensaje(positivo vs. negativo) y a la interdependencia del individuo (yo vs. otro sufriendo daños). En el primer experimento, no sólo el foco regulatorio modera la relación entre beber y convencer a los amigos a no beber y conducir, como también el frame del mensaje interactuó. En el segundo experimento, la emoción e interdependencia del individuo interactúa con el hábito de beber alcohol y afectan ambas variables dependientes.

PALABRAS CLAVE I Promoción, prevención, bebida, emoción, mensaje. 


\section{INTRODUÇÃO}

De acordo com o site do Departamento Nacional de Trânsito, um de seus objetivos é estabelecer diretrizes da Política Nacional de Trânsito com vistas à segurança, à fluidez, ao conforto, à defesa ambiental e à educação para o trânsito, além de fiscalizar seu cumprimento. No trânsito, 30\% dos socorridos em acidentes aos sábados e domingos têm sinal de embriaguez (Vasconcelos, 2013). A bebida alcoólica é responsável por $21 \%$ dos acidentes de trânsito atendidos pelo SUS (Martins, 2013). Portanto, os dados representam uma triste realidade, uma vez que a bebida alcoólica pode resultar em morte, mutilação, despesas para os cofres públicos, danos psicológicos e tantos outros problemas.

Pela perspectiva da teoria do foco regulatório (Higgins, 1987, 2000, 2006), os indivíduos utilizam processos internos para atingir objetivos pessoais. A teoria do foco regulatório propõe-se a predizer como a persuasão, por meio da manipulação das comunicações e anúncios, pode depender dos objetivos e das características pessoais do indivíduo (Lee \& Aaker, 2004). Portanto, a teoria pode ser uma lente útil nos esforços para reduzir a intenção de beber e dirigir ao ser usada para definir a estrutura da mensagem persuasiva.

Zhao e Pechmann (2007) usaram a teoria de foco regulatório e a estrutura da mensagem em comunicações para persuadir o consumo de tabaco entre os jovens. Quatro mensagens foram elaboradas e comparadas par a par. Os resultados mostraram que houve, na média, 14,4\% de aumento da intenção de não fumar quando a comunicação teve congruência com o perfil do indivíduo (vs. comparando com o grupo de controle que não recebeu estímulo algum). Esse achado empírico solidifica a implicação positiva de estruturar comunicações publicitárias de combate ao fumo em sintonia com a autorregulação.

Vieira, Citero, Pereira, Bertho, e Bustus (2013) analisaram o efeito do foco regulatório e da estrutura da mensagem sobre duas condições: a intenção de convencer os amigos a não beberem e dirigirem e a intenção de não dirigir após beber. Utilizando dois anúncios distintos, os resultados demonstraram que o foco regulatório interage com o ato de beber e que possui efeito marginal sobre a intenção de convencer os amigos a não beberem e dirigirem. Esse último resultado apresenta coerência com o texto de Zhao e Pechmann (2007), embora ainda faltem evidências.

Neste artigo, o foco principal foi examinar o impacto das mensagens do tipo não beber e dirigir, condicionada aos níveis de autorregulação do indivíduo (promoção ou prevenção), ajustando a mensagem quanto à sua estrutura (positiva ou negativa) e à emoção (culpa ou vergonha). Nesta investigação, dois experimentos foram feitos objetivando avançar nos estudos e nas limitações de Zhao e Pechmann (2007), Vieira et al. (2013) e Vieira e Ayrosa (2012), gerando quatro destaques.

Primeiro, Zhao e Pechmann (2007) analisaram uma interação tripla da autorregulação, sendo do indivíduo, da mensagem e da estrutura. Este trabalho encontrou que a estrutura dupla autorregulação do indivíduo com o ato de beber também é relevante em explicar as intenções de consumo. Segundo, Vieira et al. (2013) estruturaram comunicações com mensagens diferentes em termos de estímulos (uma com faixa de pedestre e outra com óbito). Neste artigo, as mensagens são iguais e, assim as padronizando, os resultados foram novamente encontrados. Terceiro, Agrawal e Duhachek (2010) verificaram que as condições de culpa ou vergonha tiveram relação com o consumo de bebida alcoólica. Diante disso, ampliamos a análise e verificamos que a culpa e a vergonha interagiram com a autorregulação e com a consequência e tiveram impactos na intenção de beber e dirigir e na intenção de convencer o amigo a não fazer isso. Quarto, Vieira et al. (2013) não utilizaram a consequência da mensagem como fator preditor. Como os objetivos do eu (self) independente são a autonomia e o alcance pessoal, e os objetivos do self dependente são, contrariamente, caracterizados por pertencer aos outros (Heine, Lehman, Markus, \& Kitayama, 1999), sugerimos a consequência da mensagem (eu vs. outros) e encontramos diferença nas intenções de consumo. Ademais, notamos relações significativas da autorregulação e da emoção com a consequência. 0 artigo está estruturado da seguinte forma: o referencial teórico é apresentado e, em seguida, dois experimentos são discutidos e finaliza com considerações gerais.

\section{TEORIA DO FOCO REGULATÓRIO}

De acordo com a teoria do foco regulatório, os objetivos pessoais são definidos como estruturas representativas que guiam o sistema cognitivo na busca por uma referência ou por um estado final (Higgins, 2006; Markman \& Brendl, 2000). A teoria do foco regulatório (Higgins et al., 2001) faz diferença entre duas orientações regulatórias: promoção e prevenção.

Primeiro, uma definição do foco regulatório diferencia a promoção da prevenção em termos do grau na qual dois possíveis autoguias são utilizados para regulação (Summerville \& Roese, 2008). Nessa definição, a promoção enfatiza padrões internos e a prevenção enfatiza padrões externos e sociais (Higgins, 1998). Diante disso, a promoção é definida em termos de um foco no alcance de aspirações, ambições e ideais pessoais relevantes, ou seja, um autoguia ideal (Higgins, 2000). A prevenção é compreendida em termos de obrigações e responsabilidades que são convertidas de familiares ou de outras figuras autoritárias, 
sendo aderente às regras sociais, ou seja, um guia para outros (Higgins, 1998).

A segunda definição diferencia foco em promoção daquele de prevenção com base em dois possíveis estados finais utilizados na regulação do objetivo. Um objetivo de promoção é atingido com um resultado centrado no ponto de ganho, ou seja, o ganho de obter resultados finais desejados e agradáveis, todavia o foco de prevenção é definido na regulação centrada no ponto de referência negativo de uma perda, ou seja, um objetivo desagradável e indesejável (Higgins, 1987).

De acordo com os achados de Aaker e Lee (2001), o objetivo evitar é ativado quando a pessoa está escolhendo entre opções de entretenimento pessoal com o critério de a sua escolha não ser chata (ser a menos irritante possível), quando comparada com o objetivo obter ou ganhar, o qual ativa a busca por opções de entretenimento mais excitantes. Quando o estado é positivo e desejado, os indivíduos têm um foco de obter (ex.: promoção), mas, quando o estado é negativo e indesejável, os consumidores têm um foco de evitar, ficando prevenidos (Higgins, 1987). Em suma, os indivíduos com foco em promoção foram mais persuadidos pela mensagem que gera energia, enquanto aqueles com foco em prevenção avaliaram melhor a mensagem que evita problemas (Aaker \& Lee, 2001).

Zhao e Pechmann (2007) usaram a teoria de foco regulatório e a estrutura da mensagem em comunicações para reduzir o consumo de álcool. Quando os indivíduos tinham um foco de promoção, as mensagens promocionais e sociais que promoviam parar de fumar, gerando benefícios positivos, foram mais efetivas. Quando os indivíduos tinham um foco de prevenção, gerando resultados sociais negativos, as mensagens preventivas e de desaprovação que preveniam os males e mostraram segurança foram mais efetivas.

\section{PERDAS E GANHOS}

Pesquisas sobre estrutura da mensagem evidenciam que as mensagens de foco regulatório em promoção ou prevenção podem ser apresentadas na forma de estruturas positivas e negativas, também conhecidas como estruturas de ganhos e perdas (Lee \& Aaker, 2004). Objetiva-se, portanto, aumentar o ganho e/ou evitar a perda.

0 efeito da estrutura da mensagem constitui-se na possibilidade de influenciar a decisão do indivíduo sem distorcer a informação ou suprimi-la, mas por meio de mudanças sutis na apresentação e na estruturação da informação de um mesmo problema (Tversky \& Kahnemann, 1973). Logo, por meio de alterações na forma de apresentar o problema, é possível persuadir a tomada de decisão de maneira sistemática (Mayer \& Ávila, 2000).
Por exemplo, indivíduos podem ser sensíveis a uma dada intenção negativa (tal como a de beber) se ela é estruturada em termos de custo associado (ficar doente). Outros consumidores podem ser afetuosos a uma dada intenção positiva (tal como a de não beber) se ela é estruturada em termos de ganho adjunto (ficar saudável) (Tversky \& Kahnemann, 1974). De acordo com Mayer e Ávila (2000), a função de valor da interpretação da estrutura da mensagem sugere que os indivíduos entendem os riscos relativos aos ganhos percebidos de modo distinto dos riscos que dizem respeito às perdas percebidas.

Uma estrutura positiva do anúncio deve enfatizar o resultado favorável para o consumidor do ato de cumprir a ação, mostrando o aspecto do ganho. Contudo, uma estrutura negativa enfatiza o resultado comportamental desfavorável para o indivíduo do não cumprimento da ação (Zhao \& Pechman, 2007), salientando as perdas e como elas podem ser evitadas.

Para Levin, Schneider, e Gaeth (1998) e Levin e Gaeth (1988), os objetos descritos em termos de valência positiva são geralmente avaliados mais favoravelmente do que os objetos apresentados em termos de valências negativas. Na área da saúde, esses pesquisadores mostraram que um bife descrito como $75 \%$ saudável é mais bem avaliado do que um descrito com $25 \%$ de gordura. Nota-se que a estrutura da mensagem em termos de ganhos e perdas interfere nas avaliações.

Duchon, Dunegan, e Barton (1989) alteraram a valência da mensagem (ex.: aumento de arrecadação vs. não obter arrecadação) e conseguiram mais fundos financeiros em pesquisa e desenvolvimento e menor percepção de risco percebido dos doares. Com base nesse contexto, a valência da comunicação (positiva ou ganho vs. negativa ou perda) distingue mensagens persuasivas e gera interpretações diferentes. Duas grandes estruturas teóricas discutem a valência da mensagem.

Primeiro, Rothman e Salovey (1997) sugerem que duas dimensões da valência consideram o tipo de resultado final (desejado vs. indesejado) e a ação (atingir vs. evitar), gerando uma estrutura de dois ganhos e de duas perdas $(2 \times 2)$. Na Figura 1 (lado esquerdo), quando há uma ação de atingir e um resultado desejável, então a valência da mensagem deve apresentar o ganho (célula A). Por outro prisma, quando há uma ação de atingir um resultado indesejável, então a estrutura da mensagem deve apresentar a perda (célula B).

Para Rothman e Salovey (1997), mensagens estruturadas com ganhos podem focar o atingimento de um saldo desejado ou evitar um resultado indesejável. Por exemplo, compare a mensagem: "Se você fizer uma mamografia, você terá seios mais saudáveis (ganho)" com outra mensagem: "Se você fizer mamografia, você diminuirá o risco de detectar um tumor tardiamente" (não perda). De modo similar, mensagens estruturadas 
com perdas podem enfatizar atingir um resultado indesejável ou evitar um resultado desejável. Por exemplo, compare a mensagem "Se você não fizer a mamografia, você aumentará o risco de encontrar um tumor não detectado" (resultado indesejável) com a mensagem: "Se você não fizer mamografia, você não saberá se seus seios são saudáveis" (resultado desejável).

Segundo, na estrutura de Levin e Gaeth (1988), as duas dimensões-chave são o comportamento ( $x$ vs. não x) e a estru- tura (atingir vs. evitar), criando quatro consequências, duas que envolvem ganhos e duas que envolvem perdas. Quando há uma ação $x$ e há uma estrutura positiva de atingir algo, então o resultado pode ser obter o ganho (consequência A) ou evitar a perda (consequência B). Quando há uma ação de não x e há uma estrutura negativa de evitar algo, então o resultado pode ser renunciar ao ganho (consequência $C$ ) ou sofrer a perda (consequência $D$ ).

Figura 1. Uma comparação da valência da mensagem

\begin{tabular}{|c|c|c|c|c|c|c|}
\hline \multirow{4}{*}{$\begin{array}{l}\text { Atingir } \\
\text { Ação } \\
\text { Evitar }\end{array}$} & \multicolumn{2}{|c|}{ Resultado } & & & & \multirow[b]{2}{*}{ Comportamento não $x$} \\
\hline & \multicolumn{2}{|r|}{ Indesejável } & \multirow{3}{*}{$\begin{array}{c}\text { Estrutura } \\
\text { positiva } \\
\text { (atingir) }\end{array}$} & Comportamento $\mathrm{x}$ & \multirow{3}{*}{$\begin{array}{c}\text { Estrutura } \\
\text { negativa } \\
\text { (evitar) }\end{array}$} & \\
\hline & $\begin{array}{c}\text { Estrutura de } \\
\text { ganho (Célula A) }\end{array}$ & $\begin{array}{c}\text { Estrutura de } \\
\text { perda (Célula B) }\end{array}$ & & $\begin{array}{c}\text { Obter o ganho } \\
\text { (Consequência A) }\end{array}$ & & $\begin{array}{l}\text { Renunciar o ganho } \\
\text { (Consequência C) }\end{array}$ \\
\hline & $\begin{array}{c}\text { Estrutura de } \\
\text { perda (Célula C) }\end{array}$ & $\begin{array}{c}\text { Estrutura de } \\
\text { ganho (Célula D) }\end{array}$ & & $\begin{array}{l}\text { Evitar a perda } \\
\text { (Consequência B) }\end{array}$ & & $\begin{array}{l}\text { Sofrer a perda } \\
\text { (Consequência D) }\end{array}$ \\
\hline
\end{tabular}

Fonte: Zhao e Pechmann (2007); Levin, Schneider, e Gaeth (1998).

À luz da teoria do foco regulatório (Higgins, 2006; Spiegel, Grant-Pillow, \& Higgins, 2004), os dois resultados desejáveis de Rothman e Salovey (1997) e as duas consequências envolvendo ganhos em Levin et al. (1998) são similares ao foco em promoção. Não obstante, os dois resultados indesejáveis de Rothman e Salovey (1997) e as duas consequências envolvendo perdas em Levin et al. (1998) parecem corresponder ao foco em prevenção.

\section{CULPA E VERGONHA}

Emoções normalmente variam de positivas até negativas (ex.: alegria vs. raiva) e guiam uma parcela expressiva do comportamento humano (ex.: Estou feliz com algo, logo vou às compras). Duas emoções são interessantes por serem particularmente negativas e autoconscientes, culpa e vergonha. Essas emoções são estados desagradáveis, e normalmente as pessoas buscam eliminá-las (Agrawal \& Duhachek, 2010). A vergonha pode ser sentida quando o eu do indivíduo é visto pelos olhos dos outros, tal qual o comportamento produzindo a emoção não é congruente com o comportamento do outro colega (Sauerbronn, Ayrosa, \& Barros, 2005).

A culpa é o ato repreensível ou delinquente como encargo por um ato ou, pior, por omissão repreensível ou criminosa, sendo ela toda violação de um dever jurídico, gerando, por implicação, um feito do que não se devia ter feito (Michaelis, 2014).Teorias avaliativas emocionais (Keltner, Ellsworth, \& Edwards, 1993) sugerem que pensamentos ou situações, tais como pensar que alguém pode sofrer com a ação do outro (culpa), que são consistentes com as avaliações de uma emoção, podem levar à experimentação de um estado emocional.

Há evidências de que a compatibilidade da estrutura da mensagem pode ajudar o seu entendimento quando essa é congruente com a emoção (Petty, Wegener, \& White, 1998). Diante disso, espera-se que as estruturas de comunicações possam criar maior importância pessoal para o público-alvo quando interagem com o estado emocional do consumidor, gerando um resultado mais eficaz. Portanto, as estruturas das mensagens compatíveis deveriam aumentar a persuasão, fortalecendo a intenção de mudar o comportamento do consumidor.

\section{EXPERIMENTO 1}

0 design do estudo é 2 foco regulatório (promoção vs. prevenção) × 2 consome bebida alcoólica regularmente (sim vs. não) × 2 estrutura da comunicação (negativa vs. positiva), sendo essa última manipulada entre sujeitos (Solso \& MacLin, 2001).

Os indivíduos preencheram um questionário on-line respondendo às questões do experimento. 0 questionário continha inicialmente a escala de autorregulação (promoção vs. prevenção), a qual não sofria influência do estímulo, depois as fotos do experimento com as mensagens, sendo uma foto colorida na tela de computador, posteriormente, as questões das variáveis dependentes e, por fim, as variáveis de checagem e demográficas, nessa ordem, respectivamente. 
Para encontrar os dois níveis de promoção e prevenção do foco regulatório, uma série de exames foi feita. Primeiro, uma análise fatorial exploratória foi realizada objetivando encontrar duas dimensões da autorregulação. Segundo, uma análise da confiabilidade de cada dimensão foi elaborada. Terceiro, a criação de uma média de cada fator foi estimada. Quarto, subtraiu-se o foco de promoção da prevenção, criando um escore de discrepância (isto é, um delta $\Delta$ ), gerando uma escala que varia de negativo até positivo. Quinto, por meio da mediana, dois grupos foram criados. Os escores maiores são tendências de promoção e os menores, de prevenção. Essa sistemática já foi empregada por Zhao e Peachmann (2007), Pam e Chang (2010) e Lockwood, Jordon, e Kunda (2002).

O consumo da bebida alcoólica foi encontrado via uso da questão dicotômica inserida no questionário (bebe ou não bebe bebida alcoólica regularmente), similar aos trabalhos de Vieira et al. (2013) e Vieira e Ayrosa (2012).

O estímulo da estrutura da mensagem positiva e negativa foi aplicado entre os grupos por meio de fotos. A foto continha uma latinha de cerveja amassada e com sangue, sendo que abaixo da figura a estrutura positiva apresentava as consequências positivas de não beber e dirigir. Por exemplo: "Se você não beber, obterá resultados positivos para a saúde como: melhora no fígado, aumento do desejo sexual, estabilização na taxa de açúcar no sangue e ganho de vitaminas". A valência negativa apresentava as consequências negativas de beber e dirigir. Por exemplo: "Se você não beber, evitará resultados negativos como: câncer no sistema digestivo, arritmia cardíaca, impotência sexual, e dependência do feto ao uso do álcool”. Salienta-se que as fotos foram iguais e somente os escritos foram alterados.

\section{Medições}

O foco regulatório, com 10 questões, foi mensurado por meio da escala de Lockwood et al. (2002), variando de "discordo totalmente" até "concordo totalmente", sendo metade da escala para promoção e outra metade para prevenção.

As duas variáveis dependentes foram (a) intenção de não dirigir após beber e $(b)$ intenção de convencer os amigos a não beber e dirigir. 0 procedimento de mensuração/operacionalização da pesquisa foi similar ao de Vieira et al. (2013) e Vieira e Ayrosa (2012). Para mensurar cada uma das duas variáveis dependentes, dois indicadores para cada construto foram utilizados, sendo: Após ver a mensagem, a minha probabilidade de dirigir depois de beber é (variando de "baixa" até "alta”); Após ver a mensagem, a probabilidade de beber e dirigir é (variando de "baixa" até "alta"); No que diz respeito às pessoas que dirigem após beber, eu (variando de "não ligo" até "repreendo"); e Quanto às pessoas que bebem e dirigem, eu (variando de "não ligo" até "repreendo"). As questões variaram de 1 até 7 pontos em escala do tipo Likert, as notas mais elevadas indicando aspectos positivos.

Para checar o sucesso da manipulação da valência da mensagem (manipulation check), participantes assinalaram respostas para as questões, a mensagem: (a) apresentou resultados $\mathrm{o}=$ positivos ou $1=$ negativos e $(b)$ apresentou consequências $0=$ maléficas ou 1 = benéficas. 0 exame da checagem foi feito via teste de qui quadrado $\left(x^{2}\right)$. Dados demográficos foram: sexo, idade e renda familiar bruta.

\section{RESULTADOS}

A amostra foi composta pelos internautas que responderam às questões do questionário, enviado eletronicamente para um mailing do pesquisador. 0 procedimento da amostra foi do tipo não probabilística, por conveniência e com bola de neve. Um total de 155 indivíduos respondeu ao questionário (alguns pela internet e outros pessoalmente, não havendo diferença significativa). 0 sexo feminino foi minoria, com 70 (45\%) respondentes. A média de idade foi de 34 anos (variação de 18 até 65 anos, desvio padrão $[D P]=11$ ). A renda familiar bruta foi de $R \$ 7.653,24$ (variação de $R \$ 545,00$ até $R \$ 30.000,00, D P=R \$ 6.246,52)$.

\section{Checagem dos estímulos}

Para checar o sucesso da manipulação da estrutura da mensagem, participantes utilizam respostas dicotômicas para duas questões. Quando a valência foi apresentada como negativa, os indivíduos responderam corretamente que a mensagem apresentou resultados negativos ( $v s$. positivos $x^{2}=21,36 ; p<0,000$ ) e maléficos para a saúde ( $v s$. benéficos $x^{2}=20,08 ; p<0,000$ ). Assim, as duas questões dicotômicas de checagem dos estímulos funcionaram conforme o esperado, suportando a manipulação da estrutura da mensagem.

A análise fatorial da escala de foco regulatório mostrou duas dimensões para o construto em conformidade com Lockwood et al. (2002). Exames mostraram um bom desempenho do instrumento (Kaiser Meyer Olkin (KMO) $=0,74 ; p<$ 0,000; autovalores = 3,12 e 2,09; variância explicada $=31,26 \%$ e $20,96 \%$, dos fatores promoção e prevenção, respectivamente). A Tabela 1 demonstra os resultados da rotação e das cargas fatoriais exploratórias. 
Tabela 1. Análise fatorial exploratória (Experimento 1): foco regulatório

\begin{tabular}{|c|c|c|}
\hline Variável & Promoção & Prevenção \\
\hline Eu frequentemente imagino como atingir minhas aspirações e esperanças & 0,78 & \\
\hline Eu frequentemente me imagino experimentando coisas boas que desejo que aconteçam & 0,72 & \\
\hline Eu tipicamente foco no sucesso que espero alcançar no futuro & 0,70 & \\
\hline Eu tenho receio e medo do que posso ser no futuro & & 0,75 \\
\hline Eu sou mais focado na prevenção de perdas do que em obter ganhos & & 0,71 \\
\hline Eu penso constantemente sobre como prevenir problemas na minha vida & & 0,52 \\
\hline
\end{tabular}

Nota: Componentes principais, rotação varimax (rotação oblíqua forneceu o mesmo achado); $N=155$

A matriz de associação mostra as correlações entre as variáveis, as médias em uma escala de 7 pontos e o índice de confiabilidade (Tabela 2). Os índices de Alpha de Cronbach foram acima do esperado. A variação da escala de foco regulatório foi de -2,20 até 6,00 (desvio padrão = 1,77). Em termos de associações, a média de filhos por respondente foi de o,86 (variação de o até 5), a qual não teve relação com as duas variáveis dependentes. Sexo e idade também não influenciaram significativamente as variáveis endógenas. A quantidade de pessoas que consome álcool ( $n=78 ; 50 \%$; vs. não consome) não teve relação com os indivíduos que dirigem moto ou carro $\left(n=123 ; \mathrm{x}^{2}=0,27 ; p>0,15\right)$.

Tabela 2. Matriz de correlação e médias (Experimento 1)

\begin{tabular}{|c|c|c|c|c|c|c|c|}
\hline Variável & Média & Alpha & 1 & 2 & 3 & 4 & 5 \\
\hline 1. Foco prevenção & 3,64 & 0,69 & 1 & & & & \\
\hline 3. Convencer os outros a não dirigir & 4,70 & 0,90 & $-0,07$ & 0,15 & 1 & & \\
\hline 5. Idade & 34,7 & NA & $-0,25^{\star \star}$ & 0,05 & 0,14 & $-0,02$ & 1 \\
\hline 6. Foco regulatório & 2,47 & NA & $-0,85^{\star \star}$ & $0,63^{\star \star}$ & 0,14 & 0,03 & $0,22^{* *}$ \\
\hline
\end{tabular}

Nota: ** $p<0,01 ;{ }^{*} p<0,05 ;$ NA não aplicado

\section{Efeitos principais}

Os efeitos principais (main effects) neste trabalho são os efeitos dos tratamentos, customizado sem as interações duplas, triplas ou quádruplas entre os fatores. 0 primeiro achado mostrou que as pessoas que consomem álcool regularmente (vs. não consomem) têm escores diferentes daquelas que não consomem na variável probabilidade de beber e dirigir após ver a mensagem. A probabilidade de dirigir após beber é maior para quem não bebe regularmente $\left(M_{\text {bebe }}=5,46 \mathrm{vs}\right.$. $M_{\text {nãobebe }}=6,10 ; F(1,152)=6,38 ; p$ $\left\langle 0,013 ; n^{2}=0,04\right)$. Isso pode significar que quem bebe normalmente tem um pouco mais de receio ou talvez culpa na ação de beber regularmente, não tendo tanta intenção.

Por outro lado, a intenção do indivíduo de repreender amigos e colegas pela atitude de dirigir após beber álcool é menor 
para aqueles que regularmente consomem do que para aqueles que não consomem $\left(M_{\text {bebe }}=4,28\right.$ vs. $M_{\text {não bebe }}=5,12 ; F(1,152)=$ 6,$\left.18 ; p<0,014 ; n^{2}=0,04\right)$. Portanto, os consumidores que não bebem regularmente possuem um sentimento maior de cuidado com o próximo e podem repreender tal comportamento. Esse achado é congruente com o encontrado por Vieira et al. (2013). Outra possível explicação é que os consumidores que bebem podem possuir um sentimento de "deixar pra lá" a atitude do colega, importando-se menos com os indivíduos.

Nenhum outro efeito direto foi encontrado das condições de foco regulatório $(F(1,152)=1,90 ; p>0,17$ e 1,$04 ; p>0,31)$ e da valência da comunicação $(F(1,152)=0,01 ; p>0,89$ e 0,40; $p>0,52)$ sobre as variáveis intenção de convencer os amigos e probabilidade de beber e dirigir, respectivamente. A estrutura da comunicação, embora não significativa, mostrou que as estruturas positivas de não beber tiveram os maiores escores. A comunicação positiva era a seguinte: "Se você não beber, obterá resultados positivos para a saúde como: melhora no fígado, aumento do desejo sexual, estabilização na taxa de açúcar no sangue e ganho de vitaminas".

\section{Efeitos interativos}

As interações duplas foram equacionadas e regredidas contra as duas variáveis dependentes em um modelo General Linear Model (GLM), no qual a equação foi customizada unicamente como interativa (custom model). Equações customizadas são desenhadas em uma fórmula em que apenas o efeito interativo é analisado, sem os efeitos diretos (full model) (Tabachnik \& Fidell, 2007). A soma dos quadrados foi do tipo III.

Observou-se que o foco regulatório exerce um efeito moderador na relação entre 0 ato de beber regularmente e a intenção de convencer os amigos a não dirigirem $(F(3,153)=2,97 ; p<0,03$; $n^{2}=0,06$ ). A variância explicada aumentou de $4 \%$ (sem interação) para 6\% (com interação). Quando o indivíduo não bebe regularmente, a condição de promoção gerou maior intenção de repreender o colega $\left(M_{\text {promoção }}=5,27\right.$ vs. $M_{\text {prevenção }}=5,00 ; F(1,75)=$ $0,35 ; p=\mathrm{NS})$. Quando o indivíduo bebe normalmente, a condição de promoção novamente gerou maior intenção no indivíduo de repreender o colega $\left(M_{\text {promoção }}=4,65 \mathrm{Vs}\right.$. $M_{\text {prevencãa }}=3,92 ; F(1,76)$ $=2,10 ; p<0,15)$, não obstante a diferença ficou ainda mais dilatada. Isso quer dizer que a promoção dos aspectos positivos para a saúde do ato de não beber, tais como: melhora no fígado, aumento no desejo sexual, estabilização na taxa de açúcar no sangue e ganho de vitaminas, aumentou a intenção de convencer os amigos a não dirigirem após beber (criando mais variância).

Segundo, notou-se novamente que o foco regulatório desempenha um efeito moderador na relação entre ato de beber e a probabilidade de dirigir após beber $(F(3,153)=2,60 ; p<0,05$; $\left.n^{2}=0,05\right)$. A direção das médias foi similar ao achado anterior, sendo novamente mais proeminente na promoção. A intenção do indivíduo de dirigir após beber álcool é menor para aqueles com foco na promoção. Quando o indivíduo não bebe regularmente, a condição de promoção gerou menor intenção de tomar a ação errada $\left(M_{\text {promoção }}=5,87\right.$ vs. $M_{\text {prevenção }}=6,30 ; F(1,75)=1,47$; $p<0,20)$. Quando o indivíduo bebe, as médias são bem similares em ambos os estímulos $\left(M_{\text {promoção }}=5,43\right.$ vs. $M_{\text {prevenção }}=5,48$; $F(1,75)=0,02 ; p=N S)$. Ambos os achados discutidos aqui são significativos e divergentes de Vieira et al. (2013). Uma possível explicação é que agora, utilizando comunicações padronizadas e iguais, alterando apenas os “dizeres”, foi possível encontrar relação.

Em resumo, confirma-se que a interação foco regulatório x ato de beber provoca um aumento na explicação das variáveis dependentes: intenção de convencer os amigos a não dirigir e intenção própria de dirigir. No geral, o aumento foi de $4 \%$ para $6 \%$ e de $4 \%$ para $5 \%$, respectivamente. Portanto, o consumo de bebida alcoólica é condicionado ao perfil regulatório do indivíduo em termos de promoção e prevenção, sendo mais forte na promoção (Gráfico 1).

Na sequência, testou-se a interação estrutura da mensagem $\times$ ingere bebida alcoólica regularmente sobre as duas variáveis dependentes. $A$ intenção do indivíduo de repreender os colegas pela atitude de dirigir após beber álcool foi impactada pela moderação dos fatores $\left(F(3,153)=3,15 ; p<0,027 ; n^{2}=\right.$ $0,06)$. Nota-se, portanto, que o modo de estruturar a mensagem provoca variações diferenciadas para cada perfil de consumidor. Quando o indivíduo não bebe, a condição de positiva gerou, contrariamente, maior intenção no indivíduo de repreender o colega $\left(M_{\text {positiva }}=5,62\right.$ vs. $\left.M_{\text {negativa }}=4,88 ; F(1,76)=2,53 ; p<0,11\right)$. Quando o indivíduo bebe, a condição de positiva gerou menor intenção no indivíduo de repreender o colega $\left(M_{\text {positiva }}=4,48 \mathrm{vs}\right.$. $\left.M_{\text {negativa }}=3,96 ; F(1,76)=0,95 ; p=N S\right)$. Aqui, nota-se uma interação cruzada (cross over effect). Esse achado é congruente com o de Vieira et al. (2013).

Confirmou-se também a interação estrutura da mensagem $\times$ ingere bebida alcoólica sobre a outra variável dependente, intenção de dirigir alcoolizado $\left(F(3,153)=2,92 ; p<0,036 ; n^{2}=0,05\right)$. Contudo, esse achado é contrário ao de Vieira et al. (2013). A direção das médias é apresentada no Gráfico 2. Em outras palavras, quando o público-alvo não bebe álcool, a intenção de dirigir alcoolizado é maior na estrutura negativa $\left(M_{\text {positiva }}=5,74 \mathrm{Vs}\right.$. $M_{\text {negativa }}=$ $6,28 ; F(1,76)=2,07 ; p>0,15)$. Contrariamente, quando o público-alvo bebe álcool, a intenção de dirigir alcoolizado é maior na valência positiva $\left(M_{\text {positiva }}=5,60\right.$ vs. $M_{\text {negativa }}=5,37 ; F(1,76)=$ $0,36 ; p=\mathrm{NS})$. 
Gráfico 1. Efeito do foco regulatório e do consumo de álcool sobre as duas variáveis dependentes (Experimento 1)

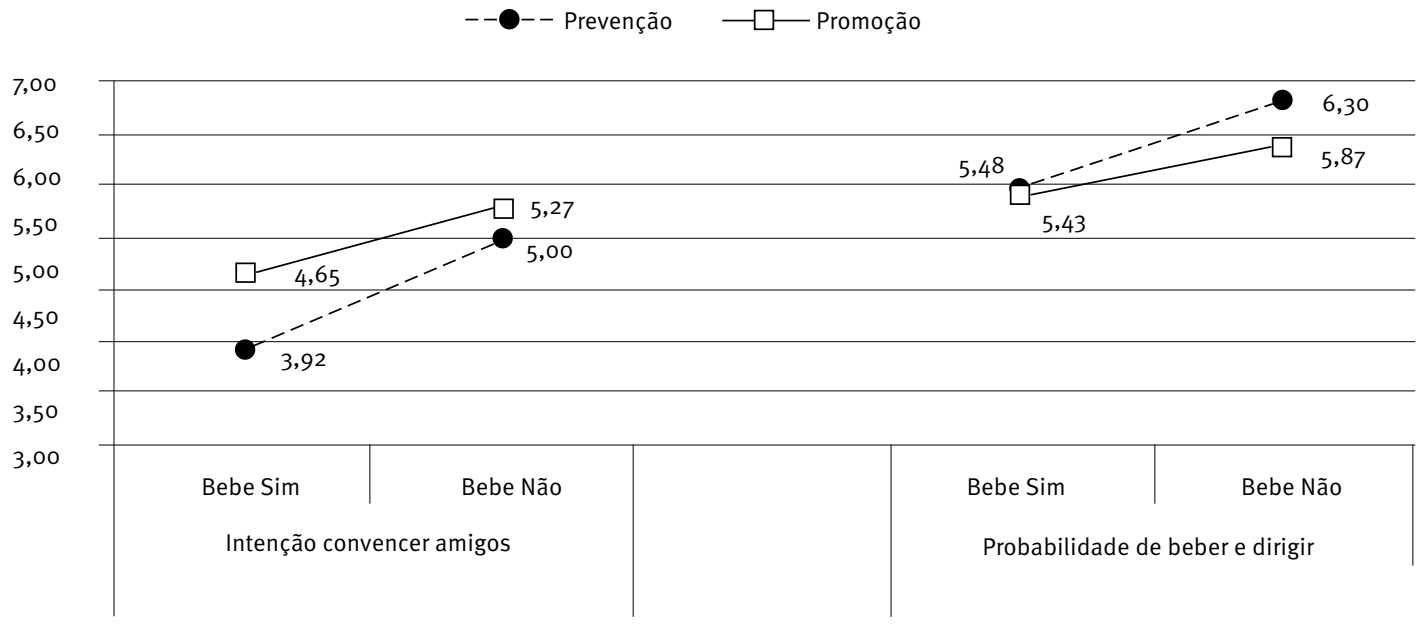

Nota: Modelo customizado para interação; as médias apresentadas na MANCOVA já estão corrigidas. As covariáveis inseridas no modelo para controle do perfil da amostra foram: probabilidade de beber e dirigir, sexo $F=0,76 ; p<0,38$; idade $F=1,30 ; p\rangle 0,25 ;$ renda $F=3,09 ; p\langle 0,08$; convencer os amigos; sexo $F=0,19 ; p\langle 0,65$; idade $F=3,60 ; p<0,06$; Renda $F=5,32 ; p>0,02$

\section{Gráfico 2. Interação estrutura da mensagem × Ingere bebida alcoólica (Experimento 1)}

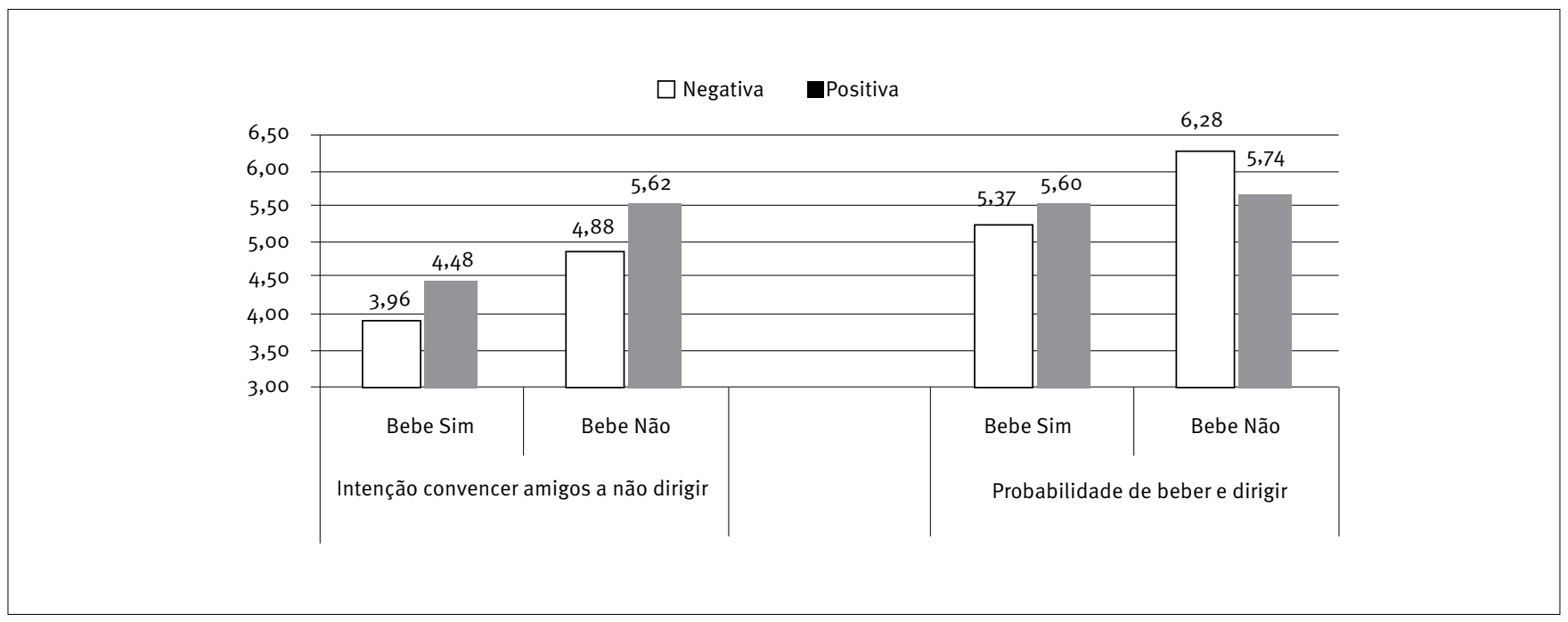

Nota: Modelo customizado para interação; as médias apresentadas na MANCOVA já estão corrigidas. As covariáveis inseridas no modelo para controle do perfil da amostra foram: probabilidade de beber e dirigir, sexo $F=0,55 ; p<0,45$; idade $F=0,77 ; p>0,38$; renda $F=3,85 ; p<0,05 ;$ convencer os amigos; sexo $F=0,13 ; p<0,71$; idade $F=2,49 ; p<0,11$; renda $F=4,33 ; p>0,03$.

Por fim, confirmou-se uma interação tripla (three way interaction) da estrutura da mensagem $\times$ ingere bebida alcoólica $\times$ foco regulatório sobre a intenção convencer os amigos a não dirigir $\left(F(7,153)=2,18 ; p<0,009 ; n^{2}=0,12\right)$ e parcialmente, ao nível de $11 \%$, sobre a intenção de dirigir após beber $\left(F(7,153)=1,70 ; p<0,11 ; n^{2}=0,08\right)$. Os resultados de Vieira et al. (2013) também são mistos. Tais achados demonstram haver uma sinergia da estrutura da mensagem $\times$ foco regulatório sobre o ato de ingerir bebida alcoólica, provocando uma interação dos três fatores (Gráfico 3). A título de comparação, o aumento de variância gerado nas variáveis dependentes foi de $4 \%$ para $12 \%$ e de $4 \%$ para $8 \%$, respectivamente. 
Gráfico 3. Interação estrutura da mensagem $\times$ Foco regulatório $\times$ Ingere bebida alcoólica (Experimento 1)

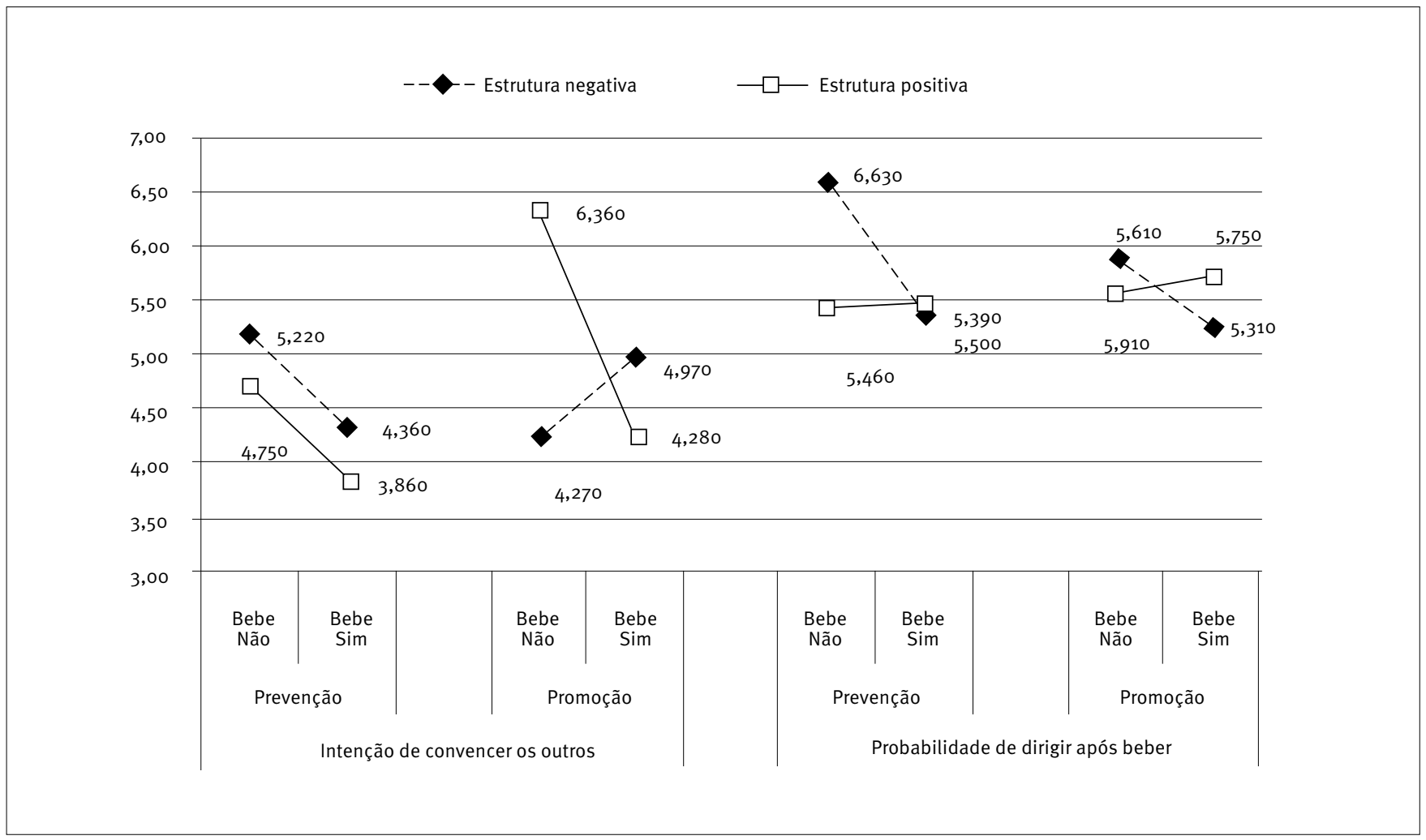

Nota: Modelo customizado para interação; as médias apresentadas na MANCOVA já estão corrigidas. As covariáveis inseridas no modelo para controle do perfil da amostra foram: probabilidade de beber e dirigir, sexo $F=1,01 ; p<0,31$; idade $F=1,29 ; p>0,25$; renda $F=3,64 ; p<0,06$; convencer os amigos; sexo $F=0,06 ; p<0,79$; idade $F=2,40 ; p<0,12$; renda $F=4,10 ; p>0,045$.

Em síntese, o primeiro estudo mostrou que, para aqueles que bebem e que não bebem, o perfil de autorregulação de promoção da vida, da saúde e do bem-estar do indivíduo gerou intenções maiores de convencer os colegas a não dirigirem alcoolizados (quando comparado ao foco regulatório de prevenção). Assim, o foco promocional foi extremamente importante.

Segundo, o estudo evidenciou que, para aqueles que não bebem, a estrutura positiva de uma comunicação de políticas públicas gerou melhores resultados. A estrutura positiva apresenta as consequências positivas de não beber e dirigir. Comunicações que apresentem argumentos tais como: "Se você não beber, obterá resultados positivos para a saúde como: melhora no fígado, aumento do desejo sexual, estabilização na taxa de açúcar no sangue e ganho de vitaminas" podem ser bem mais efetivas para conscientização. Zhao e Pechmann (2007) encontraram suporte para a autorregulação, embora usando uma interação tripla. Neste trabalho, encontramos suporte para a autorregulação utilizando uma interação dupla.

Terceiro, houve um efeito triplo da estrutura da mensagem $\times$ ingere bebida alcoólica $\times$ foco regulatório sobre a intenção convencer os amigos a não dirigirem sobre a intenção de dirigir após beber. Tal resultado suportou a noção de que a estrutura da mensagem (Levin et al., 1998; Rothman \& Salovey, 1997) pode ser condicionada aos diferentes níveis de foco regulatório do consumidor (Higgins, 1987, 2006) e ao fato de consumir bebida alcoólica. Quando o consumidor não bebe regularmente, em perfil de prevenção, a estrutura positiva foi mais relevante. Quando o consumidor não bebe regularmente, em perfil de promoção, a estrutura negativa foi mais impactante. Quando o consumidor bebe, tanto na promoção quanto na prevenção, a estrutura negativa foi mais relevante.

\section{EXPERIMENTO 2}

0 design do próximo experimento é 2 foco regulatório (promoção vs. prevenção) $\times 2$ bebe regularmente $(\operatorname{sim} v s$. não $) \times 2$ consequência (para mim vs. para outro) $\times 2$ emoção (culpa vs. vergonha), sendo os dois últimos manipulados entre sujeitos. Logo, o estudo foi um fatorial $2 \times 2 \times 2 \times 2$, sendo emoção e consequência manipulados entre grupos e as demais condições mensuradas. 
Este experimento amplia o anterior por lidar com a emoção. Determinados trabalhos (Agrawal \& Duhachek, 2010; Keltner et al., 1993; Lerner \& Keltner, 2000) sugerem que pensamentos ou situações, tais como pensar que alguém pode sofrer com a ação do outro, são consistentes com as avaliações de uma emoção, salientando julgamentos distintos. De acordo com Menon, Kyung, e Agrawal (2009), distorções dos pensamentos negativos defensivos ocorrem quando são apresentadas mensagens ao pessimismo e otimismo. Pessoas engajadas em pensamentos defensivos podem acreditar que outros colegas são suscetíveis às consequências negativas de beber (Smith \& Ellsworth, 1985). Nesse contexto, duas emoções são discutidas: culpa e vergonha.

Para checar o efeito da emoção sobre o foco regulatório, os anúncios foram mantidos iguais entre eles, alterando a estrutura argumentativa da mensagem. Há evidências de que a compatibilidade da estrutura da mensagem pode ajudar o seu entendimento quando essa é congruente com a emoção (Petty et al., 1998). Estruturas de comunicações podem criar maior importância pessoal para o público-alvo quando interagem com o estado emocional do consumidor, gerando um resultado mais eficaz. Portanto, as estruturas das mensagens compatíveis deveriam aumentar a persuasão, fortalecendo a intenção de mudar de comportamento do consumidor (Agrawal \& Duhachek, 2010).

Em termos de estímulo, a culpa é o ato repreensível ou criminoso, com responsabilidade por um ato ou por omissão repreensível ou criminoso (Michaelis, 2014). 0 anúncio com culpa e consequência para indivíduo continha o seguinte argumento: "Se for dirigir, não beba. Já imaginou ficar na cadeira de rodas devido a sua bebedeira? Não seja responsável e nem culpado por erros tolos. Não queira sentir culpa pela sua falha". 0 anúncio com culpa e com consequência para os outros continha o seguinte argumento: "Se for dirigir, não beba. Já imaginou deixar alguém na cadeira de rodas devido a sua bebedeira? Não falhe. Amigos podem sofrer. Não seja responsável e nem culpado por erros tolos. As pessoas podem sofrer com isso".

A vergonha é compreendida como a ação feita contra o decoro, contra a decência e o sentimento de desgosto que excita em nós a ideia ou o receio da desonra (Michaelis, 2014). A mensagem com o estímulo de vergonha para o indivíduo continha o seguinte conteúdo: "Se for dirigir, não beba. Já imaginou a vergonha de provocar um acidente? Você ficará arrasado. Sua autoestima estará arruinada. Você se sentirá embaraçado e sentirá vergonha do seu erro". A mensagem com o estímulo de vergonha para os outros continha o seguinte conteúdo: "Se for dirigir, não beba. Já imaginou a vergonha de provocar um acidente? Sua família ficará arra- sada. Seus colegas estarão arruinados. As pessoas ficarão embaraçadas. Não deixe seus amigos sentirem vergonha do seu erro".

Os procedimentos, as variáveis e as escalas foram todos similares ao experimento anterior. Cada grupo recebeu apenas um estímulo e respondeu às questões. Os indivíduos, após responderem às escalas dependentes, preencheram as condições de controle dos estímulos. As escalas variaram de 1 até 8 , sendo no foco regulatório do tipo "discordo totalmente" até "concordo totalmente".

\section{RESULTADOS}

Contratou-se uma empresa especializada em coleta de dados e aplicou-se o questionário no campo, em um lugar de alta circulação da cidade. A coleta foi feita em uma feira pública municipal de alto volume de tráfego em uma grande cidade. A amostra foi composta pelos consumidores que estavam passando em lugar público. Um total de 80 indivíduos escoIhidos aleatoriamente respondeu às escalas. Na feira, há aproximadamente 100 barracas e um tráfego diário de 10 mil pessoas em cada edição. A amostra de 80 pessoas foi escolhida objetivando ser igualmente distribuída entre os estímulos. O sexo feminino foi minoria, com 35 (43\%) respondentes. A média de idade foi de 33,76 anos (variação de 19 até 65 anos, DP $=10,99)$. A média da renda familiar foi de $R \$ 4.235,00$ (variação de $R \$ 850,00$ até $R \$ 15.000,00, D P=$ $\mathrm{R} \$ 3.062$,22). A média de filhos por respondente foi de 0,87 (variação de o até 5). A quantidade de pessoas que bebem regularmente foi de 56 (70\%).

Para checar o sucesso da manipulação da consequência e da emoção, testes de qui quadrado foram utilizados nas respostas dicotômicas. Quando a emoção foi de vergonha, os indivíduos responderam que a mensagem apresentou resultado vergonhoso $\left(x^{2}=54,71 ; p<0,000\right)$, confirmando. Quando a consequência foi para a pessoa (isto é, eu), os consumidores responderam que a mensagem apresentou resultado individual $\left(x^{2}=54,71 ; p<0,000\right)$. A relação entre consequência e emoção não foi expressiva $\left(x^{2}=3,16 ; p>0,80\right)$.

A análise fatorial da escala de foco regulatório, fixando 0 número de fatores em 2, apresentou duas dimensões em concordância com Lockwood et al. (2002). Achados iniciais mostraram um bom desempenho da variável (KMO =0,74; $p<0,000$; autovalores $=4,06$ e 1,92; variância explicada $=40 \%$ e 19\%, fatores promoção e prevenção, respectivamente). O valor de KMO acima de o,70 é idealmente sugerido por Rossiter (2011). A Tabela 3 demonstra os resultados. 
Tabela 3. Análise fatorial exploratória (Experimento 2)

\begin{tabular}{|c|c|c|}
\hline Variável & Promoção & Prevenção \\
\hline Eu penso sobre a pessoa que gostaria de ser no futuro & 0,84 & \\
\hline Eu normalmente foco em alcançar resultados positivos em minha vida & 0,75 & \\
\hline Por vezes, eu imagino que coisas más possam acontecer comigo no dia a dia & & 0,84 \\
\hline Eu penso constantemente sobre como prevenir problemas na minha vida & & 0,73 \\
\hline Eu tenho receio e medo do que posso ser no futuro & & 0,69 \\
\hline
\end{tabular}

Nota: Extração componentes principais, rotação varimax; teste de Bartlett $=403,64 ; p<0,000,45$ graus de liberdade; menor comunalidade 0,44 ; total de variância explicada $59,91 \%$.

A matriz de correlação não mostrou associação expressiva entre os focos de promoção e prevenção e as duas variáveis dependentes, conforme Tabela 4. A idade não impactou variável alguma.

Tabela 4. Matriz de correlação e médias (Experimento 2)

\begin{tabular}{|l|c|c|c|c|c|c|}
\hline Variável & Média & Alfa & $\mathbf{1}$ & $\mathbf{2}$ & $\mathbf{3}$ & $\mathbf{4}$ \\
\hline 1 Foco prevenção & 4,30 & 0,71 & 1 & & & \\
\hline 2 Foco promoção & 5,92 & 0,87 & $0,34^{\star}$ & 1 & & \\
\hline 3 Convencer os outros a não dirigir & 4,41 & 0,95 & 0,02 & $-0,08$ & 1 & \\
\hline 4 Probabilidade de eu dirigir alcoolizado & 3,76 & 0,97 & $-0,14$ & 0,02 & 0,10 & 1 \\
\hline 5 Foco regulatório & 1,62 & 0,79 & $-0,67^{\star \star}$ & $0,46^{\star \star}$ & $-0,04$ & 0,15 \\
\hline 6 Idade & 33,76 & & $-0,14$ & 0,03 & 0,06 & $-0,01$ \\
\hline
\end{tabular}

Nota: Correlação de Pearson, ${ }^{* *} p<0,01 ;{ }^{*} p<0,05$; escala de 1 a $8 ; n=80$; Alfa de Cronbach

Primeiramente, os efeitos diretos dos tratamentos foram examinados no modelo GLM customizado. 0 foco regulatório, a consequência da mensagem e a emoção não se relacionaram com as duas variáveis dependentes. 0 ato de beber teve relação apenas com a probabilidade de dirigir após beber $(F(1,79)$ $\left.=76,72 ; p<0,000 ; n^{2}=0,47\right)$. Portanto, dos quatro tratamentos, três não impactam a intenção de ação do consumidor.

Conforme o esperado, os resultados mostraram uma relação significativa da interação do foco regulatório $\times$ bebe sobre a probabilidade de dirigir após beber $(F(7,79)=24,32$; $\left.p<0,000 ; n^{2}=0,49\right)$, mas não sobre a intenção de convencer os colegas a não dirigir após beber $\left(F(7,79)=1,30 ; p<0,27 ; n^{2}\right.$ $=0,05)$. Vieira et al. (2013) não acharam efeito em ambas as condições, e nos dois estudos aqui realizados encontramos suporte para a intenção de beber e dirigir. Especificamente, quando o consumidor não bebe, a condição de prevenção gerou maior intenção no indivíduo de tomar a ação errada $\left(M_{\text {pro. }}\right.$. moção $=1,27$ Vs. $\left.M_{\text {prevenção }}=1,58 ; F(1,23)=0,55 ; p>0,80\right)$. Quando o indivíduo bebe, o estímulo de promoção gerou maior intenção no indivíduo de tomar a ação errada $\left(M_{\text {promocão }}=4,93\right.$ vs. $\left.M_{\text {prevenção }}=4,54 ; F(1,55)=0,69 ; p>0,40\right)$. Quando o consumidor não bebe, contrariamente, a classe de prevenção gerou maior intenção de convencer os amigos a não praticar o ato errado $\left(M_{\text {promoção }}=3,63\right.$ vs. $M_{\text {prevenção }}=5,12 ; F(1,23)=1,60 ; p$ < $0,21)$. Ademais, quando o indivíduo bebe, o foco de promoção gerou maior intenção de convencer os amigos a não praticar o ato errado $\left(M_{\text {promoção }}=4,64\right.$ Vs. $M_{\text {prevenção }}=3,95 ; F(1,55)=1,72$; $p>0,19$; ver Gráfico 4). 
Gráfico 4. Interação dupla de foco regulatório vs. beber (Experimento 2)

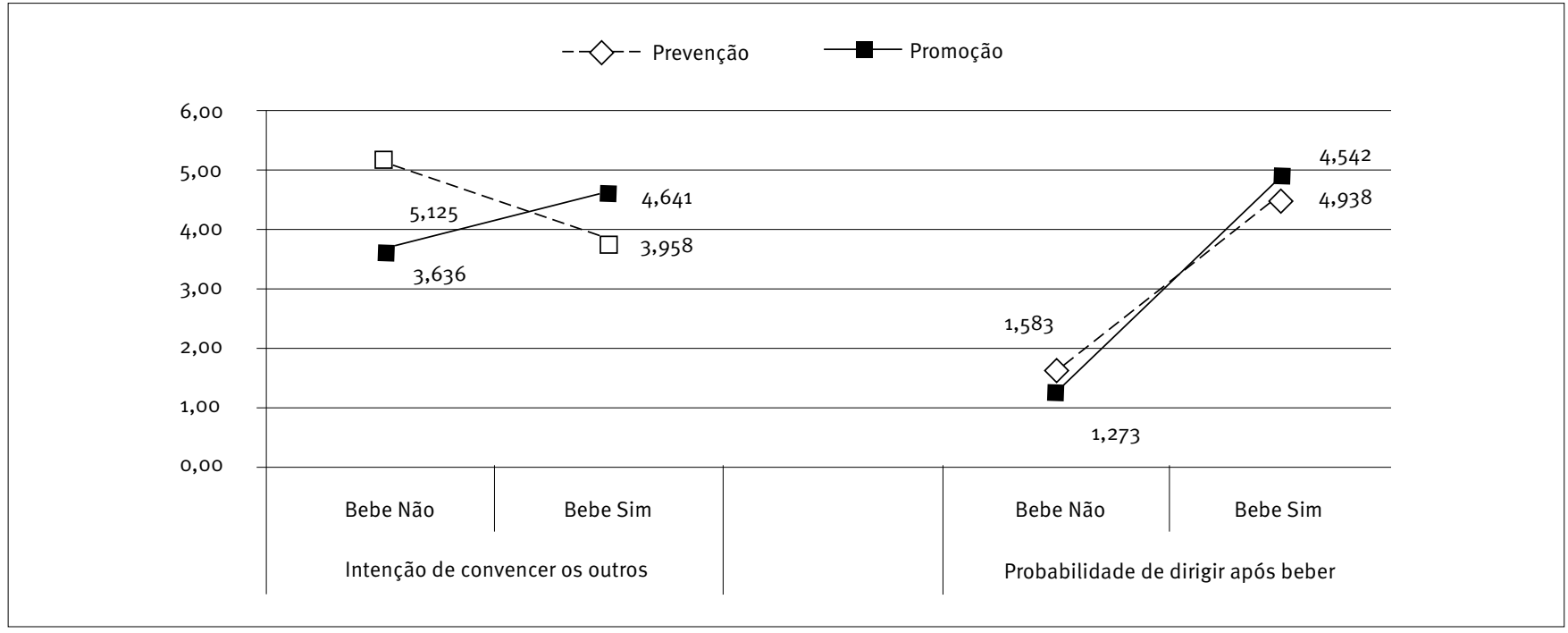

Nota: Modelo customizado para interação; as médias apresentadas na MANCOVA já estão corrigidas. As covariáveis inseridas no modelo para controle do perfil da amostra foram: probabilidade de beber e dirigir, sexo $F=0,78 ; p<0,38$; idade $F=0,18 ; p\rangle 0,67$; renda $F=1,85 ; p<0,17$; filhos $F=1,31 ; p<0,25$; convencer os amigos; sexo $F=0,78 ; p<0,39$; idade $F=0,08 ; p<0,76$; renda $F=0,00 ; p>0,94$.

Não obstante, a interação dupla de foco regulatório $\times$ beber encontrada anteriormente foi amplificada, agora com a adição da condição emocional (Agrawal \& Duhachek, 2010). Portanto, quando a emoção foi adicionada à interação dupla, gerando uma interação tripla (foco regulatório $\times$ emoção $\times$ bebe), houve um aumento expressivo da variância explicada. Esse exame triplo não foi feito por Vieira et al.(2013) uma vez que não estudaram as emoções culpa e vergonha.

Os achados mostraram uma relação significativa de foco regulatório $\times$ emoção $\times$ bebe sobre a probabilidade de dirigir após beber $\left(F(7,79)=10,70 ; p<0,000 ; n^{2}=0,53\right.$ antes $\left.\mathrm{R}^{2}=0,49\right)$ e sobre a intenção de convencer os colegas a não dirigir após beber $\left(F(7,79)=2,25 ; p<0,04 ; n^{2}=0,18\right.$ antes $\left.\mathrm{R}^{2}=0,05\right)$. Para compreender a interação tripla, é necessário fixar os dois grupos da emoção, vergonha e culpa, e depois analisar os dados isoladamente. Especificamente, para quem bebe e vê a comunicação de culpa, a intenção do indivíduo de repreender o colega é maior na promoção $\left(M_{\text {promoção }}=4,84\right.$ Vs. $M_{\text {prevenção }}=3,91 ; F(1,25)=1,23 ; p$ $>0,27)$. Para quem bebe e nota a comunicação de culpa, a intenção do indivíduo de beber e dirigir é maior na prevenção $\left(M_{\text {promoção }}\right.$ $=4,50$ vs. $\left.M_{\text {prevenção }}=4,83 ; F(1,25)=0,19 ; p>0,76\right)$. Para quem não bebe e vê a comunicação de culpa, a intenção do consumidor de repreender o colega é maior na prevenção $\left(M_{\text {promoção }}=2,66\right.$ vs. $\left.M_{\text {prevenção }}=6,37 ; F(1,13)=14,24 ; p<0,00\right)$. Para quem não bebe e vê a comunicação de culpa, a intenção do indivíduo de beber e dirigir é maior na prevenção $\left(M_{\text {promoção }}=1,50\right.$ vs. $M_{\text {prevenção }}=1,75$; $F(1,13)=0,13 ; p>0,73)$. Quando a emoção é a vergonha de ter causado 0 acidente, as decorrências são as seguintes: Para quem bebe e vê a comunicação de vergonha, a intenção do indivíduo de repreender o colega é maior na promoção $\left(M_{\text {promoção }}=4,50\right.$ vs. $\left.M_{\text {prevenção }}=4,00 ; F(1,31)=0,54 ; p>0,38\right)$. Para quem bebe $\mathrm{e}$ observa à comunicação de vergonha, a intenção do indivíduo de beber e dirigir é maior na prevenção $\left(M_{\text {promoção }}=5,23\right.$ Vs. $M_{\text {pre. }}$ venção $=4,25 ; F(1,31)=2,59 ; p<0,11)$. Para quem não bebe e vê a comunicação de vergonha, a intenção do indivíduo de repreender o colega é maior na promoção $\left(M_{\text {promoção }}=4,80 \mathrm{vs}\right.$. $M_{\text {prevenção }}=$ 2,62; $F(1,9)=0,96 ; p>0,29)$. Para quem não bebe e vê a comunicação de vergonha, a intenção do indivíduo de beber e dirigir é maior na prevenção $\left(M_{\text {promoção }}=1,00\right.$ vs. $M_{\text {prevenção }}=1,25 ; F(1,9)$ $=1,29 ; p<0,29)$, conforme Gráfico 5 .

Os resultados mostraram uma relação significativa da interação tripla emoção × consequência da mensagem sobre a intenção de convencer os colegas a não dirigir após beber e probabilidade de dirigir após beber $\left(F(3,79)=5,41 ; p<0,002 ; n^{2}=\right.$ $0,17)$, mas não sobre a probabilidade de dirigir após beber $(F(3,79)$ $\left.=0,89 ; p<0,45 ; n^{2}=0,03\right)$. Essa interação dupla encontrada foi amplificada pela condição de beber, onde a consequência $x$ emoção $\times$ bebe exerceu efeito sobre a probabilidade de dirigir após beber $\left(F(7,79)=12,02 ; p<0,000 ; n^{2}=0,54 ;\right.$ poder $\left.=1\right) \mathrm{e}$ sobre a intenção de convencer os colegas a não dirigir após beber $\left(F(7,79)=5,96 ; p<0,000 ; n^{2}=0,36 ;\right.$ poder $\left.=0,99\right)$.

Para quem bebe, a intenção do indivíduo de repreender o colega é maior na condição de culpa individual $\left(M_{\operatorname{mim}}=4,90 \mathrm{vs}\right.$. $\left.M_{\text {outros }}=4,00 ; F(1,25)=1,16 ; p>1,11\right)$. Para quem bebe, a intenção do indivíduo de consumidor é maior na condição de culpa para os outros $\left(M_{\text {mim }}=4,27\right.$ vs. $M_{\text {outros }}=4,96 ; F(1,25)=0,85 ; p$ > $0,89)$. Para quem não bebe, a intenção do indivíduo de repreender o colega é maior na condição de culpa individual $\left(M_{\operatorname{mim}}=\right.$ 
6,00 vs. $\left.M_{\text {outros }}=2,60 ; F(1,14)=8,97 ; p<0,01\right)$. Para quem não bebe, a intenção do consumidor é maior também na qualidade de culpa individual $\left(M_{\text {mim }}=2,00\right.$ vs. $\left.M_{\text {outros }}=1,00 ; F(1,14)=2,41 ; p<0,14\right)$. Quando a emoção é a vergonha de ter causado o acidente, os resultados são os seguintes: Para quem bebe, a intenção do consumidor de repreender o colega é maior na condição de vergonha para os outros $\left(M_{\text {mim }}=4,03\right.$ vs. $\left.M_{\text {outros }}=4,56 ; F(1,31)=0,64 ; p>0,33\right)$. Para quem bebe, a intenção do indivíduo de consumir é maior também na condição de vergonha para os outros $\left(M_{\text {mim }}=4,33\right.$ vs. $\left.M_{\text {outros }}=5,34 ; F(1,31)=2,89 ; p<0,10\right)$. Para quem não bebe, a intenção do indivíduo de repreender o colega é maior na condição de vergonha para os outros $\left(M_{\text {mim }}=1,10\right.$ vs. $M_{\text {outros }}=7,40 ; F(1,10)$ $=233,47 ; p<0,000)$. Para quem não bebe, a intenção do consumidor de consumir é maior também na classe de vergonha individual $\left(M_{\text {mim }}=1,20\right.$ vs. $\left.M_{\text {outros }}=1,00 ; F(1,10)=1,00 ; p>1,13\right)$. (Ver Gráfico 6).

\section{Gráfico 5. Interação tripla emoção vs. foco regulatório vs. beber (Experimento 2)}

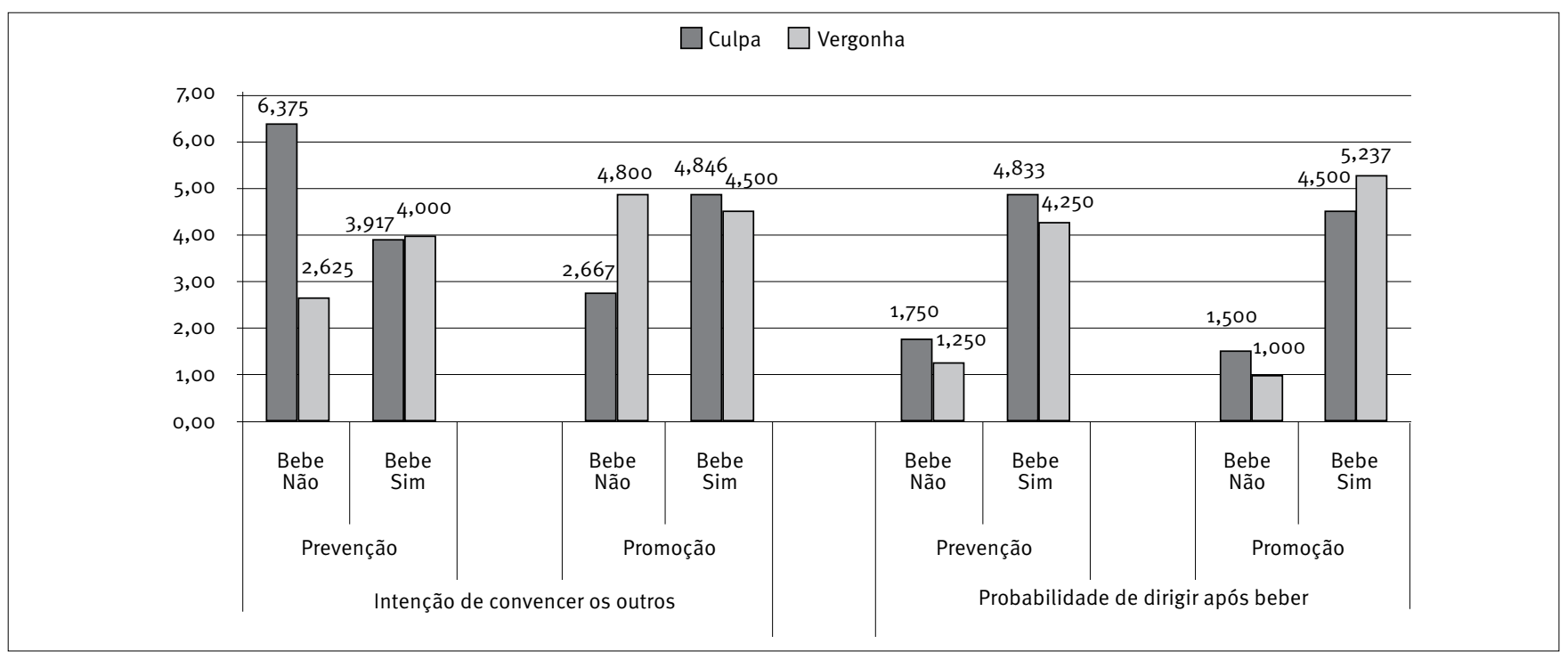

Nota: As médias apresentadas na MANCOVA já estão corrigidas. As covariáveis inseridas no modelo para controle do perfil da amostra foram: probabilidade de beber e dirigir, sexo $F=0,08 ; p<0,77$; idade $F=0,80 ; p>0,37$; renda $F=1,44 ; p<0,23$; filhos $F=1,84 ; p<0,17$; convencer os amigos; sexo $F=0,78 ; p<0,37 ;$ idade $F=0,21 ; p<$ o,64; renda $F=0,03 ; p>0,84$.

\section{Gráfico 6. Interação tripla emoção vs. consequência vs. beber (Experimento 2)}

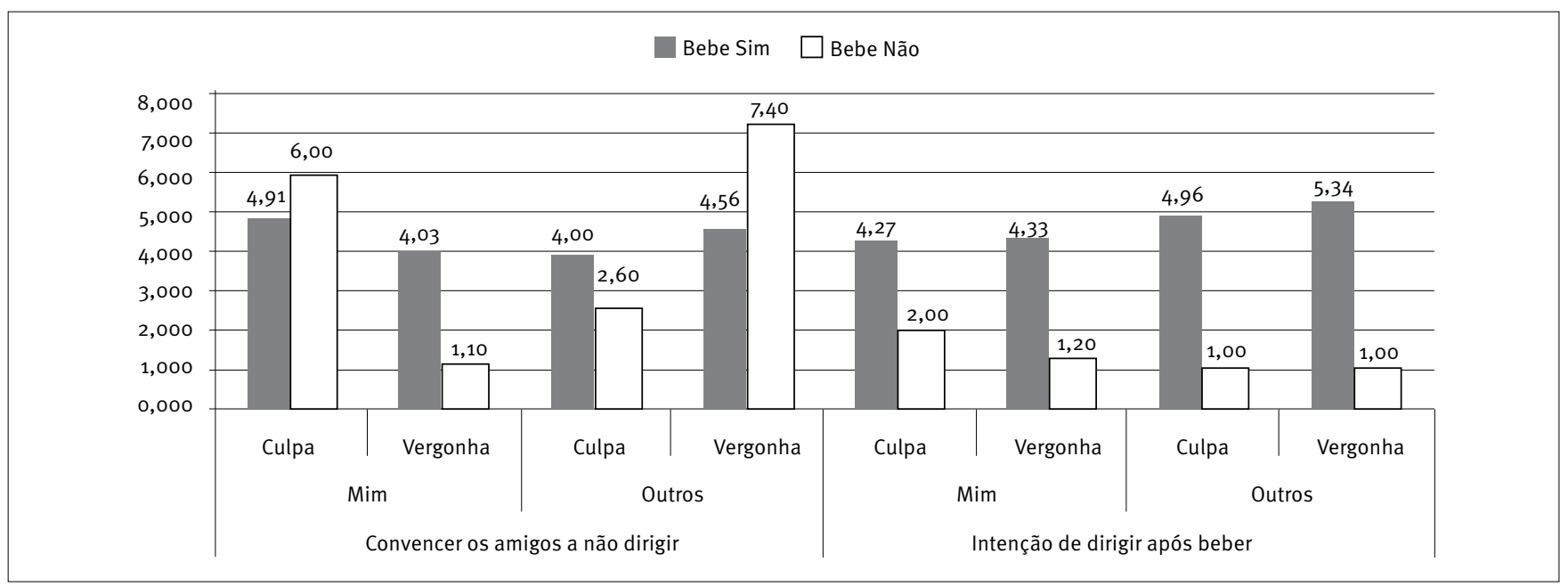

Nota: As médias apresentadas na MANCOVA já estão corrigidas. As covariáveis inseridas no modelo para controle do perfil da amostra foram: probabilidade de beber e dirigir, sexo $F=0,84 ; p<0,36$; idade $F=0,66 ; p>0,41$; renda $F=0,82 ; p<0,36$; filhos $F=2,20 ; p<0,14$; convencer os amigos; sexo $F=1,27 ; p<0,23 ;$ idade $F=1,34 ; p<$ 0,26 ; renda $F=0,41 ; p>0,52$. 
Por fim, a consequência mostrou-se novamente relevante, pois interagiu com o foco regulatório. Os resultados mostraram uma relação significativa da interação do foco regulatório × consequência da mensagem sobre a probabilidade de dirigir após beber $\left(F(3,79)=2,77 ; p<0,047 ; n^{2}=0,10\right)$, mas não sobre a intenção de convencer os colegas a não dirigir após beber $(F(7,79)=0,06 ; p<$ 0,$\left.97 ; n^{2}=0,00\right)$. Pesquisas mostram que a diferença na autodependência do indivíduo pode ser ativada e, consequentemente, alterar as atitudes e as decisões, salientando que o eu do ser humano é maleável (Kleine, Kleine, \& Kernan, 1993; Lee \& Aaker, 2004).

Em síntese, os resultados do Experimento 2 mostraram uma relação significativa do foco regulatório $\times$ bebe sobre a probabilidade de dirigir após beber e uma relação parcial sobre a intenção de convencer os colegas a não dirigirem após beber. Primeiro, quando o indivíduo não bebe, a condição de prevenção gerou maior vontade de convencer os amigos a não praticar o ato errado. Segundo, quando o indivíduo bebe, a condição de promoção gerou maior intenção de convencer os amigos a não praticar o ato errado. Terceiro, a interação observada anteriormente foi amplificada com a adição da emoção de culpa e de vergonha, surgindo como novos elementos em explicar a intenção de dirigir após beber e convencer os colegas a não dirigirem após beber. De fato, a emoção também surgiu como um estímulo relevante, pois interage com a consequência da mensagem, em linha com os trabalhos de Kitayama e Cohen (2007) e Fiske, Kitayama, Markus, e Nisbett (1998).

\section{CONCLUSÕES}

Inicialmente, este trabalho analisou o impacto do ato de ingerir bebida alcoólica sobre a intenção dos consumidores e como o foco regulatório pode interferir nessa relação. Os dois experimentos aqui elaborados, somados aos achados de Vieira et al. (2013) e Vieira e Ayrosa (2012), mostraram que o ato de beber interfere na intenção de beber e dirigir, sendo menor para quem bebe regularmente. Isso pode ser devido às emoções de culpa e de vergonha associadas ao comportamento incoerente e ilegal de dirigir embriagado (Sauerbronn et al., 2005). Tais emoções são estados desagradáveis, e normalmente as pessoas buscam eliminá-los, sendo relacionados com a intenção de beber (Agrawal \& Duhachek, 2010).

Segundo, os experimentos aqui realizados mostraram que o foco regulatório aumentou a variância explicada da variável intenção de convencer os amigos. Para quem bebe, a mensagem de promoção da vida aumenta a intenção de convencer os amigos a não errarem. Por outro lado, para quem bebe, a mensagem de promoção ou de prevenção não gerou diferença sobre a intenção. Vale salientar que, no estudo de Vieira et al. (2013), o resultado não foi significativo, contudo, no primeiro experimento, foi expressivo para ambas as variáveis e, no segundo experimento, foi significativo apenas para o indivíduo, e não para o colega. Portanto, os achados foram mistos e precisam ser vistos com cautela. 0 maior poder para convencer os amigos a não dirigirem após beber veio da estrutura positiva. Todavia, quando o resultado é para si próprio, a melhor combinação é a negativa.

Terceiro, a interação do foco regulatório com o ato de beber ficou ainda mais evidente com a adição de um terceiro elemento, a estrutura (framing). 0 estudo de Vieira et al. (2013) salientou esse achado, e este estudo comprovou novamente a interação do frame com o ato de beber e parcialmente com a intenção de convencer os amigos. Contudo, como se observou, as médias foram em direções diferentes. Uma explicação pode ser a alteração dos estímulos entre os estudos.

Quarto, a utilização da emoção de culpa e vergonha do consumidor, já discutida em texto de Sauerbronn et al. (2005) e aplicada no trabalho de Agrawal e Duhachek (2010), mostrou-se uma possível lente para explicar a interação entre beber e foco regulatório, pois a interação tripla foi evidenciada. Agrawal e Duhachek (2010) examinaram a interação entre vergonha e culpa e a compatibilidade da mensagem sobre a intenção de beber. Para esses autores, as mensagens que são compatíveis, as quais geram as mesmas emoções experimentadas pelos consumidores, são menos efetivas em influenciar a intenção de beber. Nós examinamos a interação entre vergonha e culpa e a consequência/autorregulação sobre a intenção de beber. Tomando por base apenas os indivíduos que não bebem, os resultados aqui mostraram que a culpa e prevenção auxiliam a intenção de convencer os amigos a não dirigirem. Por outro lado, tomando por base apenas os indivíduos que não bebem, os achados aqui mostraram que a vergonha e promoção geram maiores escores na intenção de convencer os amigos a não dirigirem.

Quinto, pesquisa em psicologia cultural (Kitayama \& Cohen, 2007) tem focado esforços na distinção entre dois tipos de autovisualização: dependente e independente (Fiske et al., 1998). 0 foco independente refere-se à visualização pessoal definida por atributos únicos e características, tais como a atitude, que diferencia uma pessoa de outra. 0 foco dependente, por outro lado, refere-se à visualização pessoal definida pelo que os outros pensam, ao ponto de se diferenciar dos outros, encorajando valores de obrigações e de responsabilidades sobre os desejos dos outros. Os resultados do nosso trabalho mostraram que a consequência interagiu com a emoção, com a autorregulação e com ambas as condições para explicar a intenção de convencer os amigos. Aqui, abre-se um novo caminho para futuras pesquisas estruturarem comunicações que mostrem consequências dependentes ou independentes das ações do consumidor. 
Em termos de limitação, o trabalho utilizou modelos interativos customizados para examinar as hipóteses. Estimar equações com modelos completos pode gerar resultados diferentes. Outra limitação é utilizar as mensagens em conjunto com fotos. Especificamente, a foto da latinha de sangue é negativa com um texto de promoção, pois o sangue pode ter interferido na avaliação do respondente. Além disso, os estímulos dos dois experimentos neste trabalho foram iguais, manipulando apenas o texto. Por outro lado, Vieira et al. (2013) utilizaram também estímulos com fotos iguais, mas com texto diferente. 0 trabalho, ainda, manipulou o foco regulatório e o ato de beber, fazendo uma análise por meio dos grupos criados de acordo com as respostas. Há possibilidade de criar grupos por meio de histórias de promoção e de prevenção e novos estudos podem utilizar esse procedimento, conforme feito por Zhao e Pechmann (2007). Por fim, há uma limitação no tamanho da amostra no segundo experimento; ainda que suficiente para estimar interações duplas ou triplas, a amostra ainda é pequena para estimar modelos completos (full models), devido à quantidade de parâmetros.

\section{NOTA DE AGRADECIMENTO}

Os autores são gratos aos comentários do Editor chefe, dos avaliadores, dos professores André T. Urdan, Eduardo B. Andrade, Francisco G. D. Vieira, Victor Almeida e Vinícius A. Brei, ao suporte financeiro da Fundação Araucária de Pesquisa e ao auxílio de Kelly Bustos, Flávia Pereira, Giovana Bertho e Daniel Citero.

\section{REFERÊNCIAS}

Aaker, J. L., \& Lee, A. Y. (2001). "I” seek pleasure and "we" avoid pains: The role of self-regulatory goals in information processing and persuasion. Journal of Consumer Research, 28(1), 33-44. doi:10.1086/321946

Agrawal, N., \& Duhachek, A. (2010). Emotional compatibility and the effectiveness of antidrinking messages: A defensive processing perspective on shame and guilt. Journal of Marketing Research, 47(2), 263-273. doi:10.1509/jmkr.47.2.263

Duchon, D., Dunegan, K. J., \& Barton, S. L. (1989). Framing the problem and making decisions: The facts are not enough. Engineering Management, IEEE Transactionson, 36(1), 25-27. doi:10.1109/17.19979

Fiske, A., Kitayama, S., Markus, H. R., \& Nisbett, R. (1998). The cultural matrix of social psychology. In D. T. Gilbert, \& S. T. Fiske (Eds.). Handbook of social psychology (Vol. 2, pp. 915-981). Boston: McGraw-Hill.

Heine, S. J., Lehman, D. R., Markus, H. R., \& Kitayama, S. (1999). Is there a universal need for positive self-regard? Psychological Review, 106(4), 766-794. doi:10.1037/0033-295X.106.4.766
Higgins, E. T. (1987). Self-discrepancy: A theory relating self and affect. Psychological Review, 94(3), 319-340. doi:10.1037/0033$295 \times \cdot 94 \cdot 3 \cdot 319$

Higgins, E. T. (1998). Promotion and prevention: Regulatory focus as a motivational principle. In M. E. Zanna (Ed.). Advances in experimental social psychology (Vol. 30, pp.1-46). New York: Academic Press.

Higgins, E. T. (2000). Making a good decision: Value from fit. American Psychologist, 55(11), 1217-1230. doi:10.1037/0003-066x.55.11.1217

Higgins, E. T. (2006). Valor from hedonic experience and engagement. Psychological Review, 113(3), 439-460. doi:10.1037/0033295x.113.3.439

Higgins, E. T., Friedman, R., Harlow, R., Idson, L., Ayduk, O., \& Taylor, A. (2001). Achievement orientations from subjective histories of success: Promotion pride versus prevention pride. European Journal of Social Psychology, 31(1), 3-23. doi:10.1002/ejsp.27

Keltner, D., Ellsworth, P. C., \& Edwards, K. (1993). Beyond simple pessimism: Effects of sadness and anger on social perception. Journal of Personality and Social Psychology, 64(5), 740-752. doi:10.1037/0022-3514.64.5.740

Kitayama, S., \& Cohen, D. (2007). Handbook of cultural psychology. New York: Guilford Press.

Kleine, R. E., Kleine, S. S., \& Kerman, J. B. (1993). Mundane consumption and the self: A social identity perspective. Journal of Consumer Psychology, 2(3), 209-235. doi:10.1016/S1057-7408(08)80015-0

Lee, A. Y., \& Aaker, J. (2004). Bringing the frame into focus: The influence of regulatory fit on processing fluency and persuasion. Journal of Personality and Social Psychology, 86(2), 205-218. doi:10.1037/0022-3514.86.2.205

Lerner, J. S., \& Keltner, D. (2000). Beyond valence: Toward a model of emotion-specific influences on judgment and choice. Cognition \& Emotion, 14(4), 473-493. doi:10.1080/026999300402763

Levin, I. P., \& Gaeth, G. J. (1988). How consumers are affected by the framing of attribute information before and after consuming the product. Journal of Consumer Research, 15(3), 374-378.

Levin, I. P., Schneider, S. L., \& Gaeth, G.J. (1998). All frames are not created equal: A typology and critical analysis of framing effects. Organizational Behavior and Human Decision Process, 76(2), 149188. doi:10.1006/obhd.1998.2804

Lockwood, P., Jordan, C. H., \& Kunda, Z. (2002). Motivation by positive or negative or negative role models: Regulatory focus determines who will best inspire us. Journal of Personality and Social Psychology, 83(4), 854-864.

Markman, A. B., \& Brendl, M. C. (2000). The influence of goals on value and choice. In D. L. Medin (Ed.). The psychology of learning and motivation (Vol. 39, pp. 97-129).San Diego, CA: Academic Press.

Martins, C. (2013). Bebida alcoólica é responsável por $21 \%$ dos acidentes de trânsito atendidos pelo SUS. Portal R7. Recuperado de http://noticias.r7.com

Mayer, V. F., \& Ávila, M. G. (2000). A influência da estruturação da mensagem em comportamentos relacionados à saúde: Um teste experimental. Anais do $24^{\circ}$ Encontro da Associação de PósGraduação e Pesquisa em Administração, Florianópolis.

Menon, G., Kyung, E. J., \& Agrawal, N. (2009). Biases in social comparisons: Optimism or pessimism?. Organizational Behavior and Human Decision Process, 108(1), 39-52. doi:10.1016/j. obhdp.2008.05.001

Michaelis. (2014). Moderno dicionário da língua portuguesa. Recuperado de http://michaelis.uol.com.br/moderno/portugues/ index.php

Pam, M. T., \& Chang, H.H. (2010). Regulatory focus, regulatory fit, and the search and consideration of choice alternatives. Journal of Consumer Research, 37(4), 626-640. doi:10.1086/655668 
Petty, R. E., Wegener, D. T., \& White, P. H. (1998). Flexible correction processes in social judgment: Implications for persuasion. Social Cognition, 16(1), 93-113. doi:10.1521/soco.1998.16.1.93

Rossiter, J. R. (2011). Marketing measurement revolution: The C-OAR-SE method and why it must replace psychometrics. European Journal of Marketing, 45(11/12), 1561-1588. doi:10.1108/03090561111167298

Rothman, A. J., \& Salovey, P. (1997). Shaping perceptions to motivate healthy behavior: The role of message framing. Psychological Bulletin, 121(1), 3-19. doi:10.1037/0033-2909.121.1.3

Sauerbronn, J. F. R., Ayrosa, E. A. T., \& Barros, D. F. (2005). O consumidor envergonhado: Reflexões sobre o sentimento de vergonha no marketing. Cadernos EBAPE.BR, 3(2), 1-11. doi:10.1590/s167939512005000200009

Smith, C. A., \& Ellsworth, P. C. (1985). Patterns of cognitive appraisal in emotion. Journal of Personality and Social Psychology, 48(4), 813838. doi:10.1037/0022-3514.48.4.813

Solso, R. L., \& MacLin, M. K. (2001). Experimental psychology: A case approach (7th ed.). New Jersey: Prentice Hall.

Spiegel, S., Grant-Pillow, H., \& Higgins, E. (2004). How regulatory fit enhances motivational strength during goal pursuit. European Journal of Social Psychology, 34(1), 39-54. doi:10.1002/ejsp.180

Summerville, A., \& Roese, N. J. (2008). Self-report measures of individual differences in regulatory focus: A cautionary note. Journal of Research in Personality, 42(1), 247-254. doi:10.1016/j.jrp.2007.05.005
Tabachnick, G. G., \& Fidell, L. S. (2007). Experimental designs using ANOVA. Belmont, CA: Duxbury.

Tversky, A. \& Kahneman, D. (1973). Availability: A heuristic for judging frequency and probability. Cognitive Psychology, 5 (2), 207-232. doi:10.1016/0010-0285(73)90033-9

Tversky, A., \& Kahneman, D. (1974). Judgment under uncertainty: Heuristics and biases. Science, 185(4157), 1124-1131. doi:10.1126/ science.185.4157.1124

Vasconcellos, F. (2013, junho 11). No trânsito, 17\% dos socorridos em acidentes têm sinal de embriaguez. O Globo. Recuperado de http:// oglobo.globo.com

Vieira, V. A., \& Ayrosa, E. A. T. (2012). O efeito moderador do foco regulatório nas campanhas contra o álcool: Minimizando a intenção de beber e dirigir. Anais do $36^{\circ}$ Encontro Anual da Associação Nacional de Pós-Graduação e Pesquisa em Administração, Rio de Janeiro.

Vieira, V. A., Citero, D. B., Pereira, F. O., Bertho, G. S., \& Bustus, K. C. (2013). Intenção de beber e dirigir dos consumidores. Caderno de Administração, 21(2), 19-29.

Zhao, G., \& Pechmann, C. (2007). The impact of regulatory focus on adolescents' response to antismoking advertising campaigns. Journal of Marketing Research, 44(4), 671-687. doi:10.1509/jmkr.44.4.671 